\title{
Injection site rotation
}

National Diabetes Information Clearinghouse (NDIC)

\section{Definitions}

Insulin

Defined by National Diabetes Information Clearinghouse (NDIC)

Lipodystrophy

Defined by National Diabetes Information Clearinghouse (NDIC)

Source

National Diabetes Information Clearinghouse (U.S.). (2009). The diabetes dictionary. [Bethesda, Md.]: U.S. Dept. of Health and Human Services, National Institutes of Health, National Institute of Diabetes and Digestive and Kidney Diseases, National Diabetes Information Clearinghouse.

Changing the places on the body where insulin is injected. Rotation prevents the formation of lipodystrophies. 